\title{
Wu-wei and Wu-zhi in Daodejing: An Ancient Chinese Epistemological View on Learning
}

\author{
Lei Xie \\ Texas A\&M University
}

\begin{abstract}
Daodejing, one of the most influential books in China was written by one of the greatest philosophers in ancient China, an elder contemporary of Confucius, Laozi. Daodejing was mainly the records of the observation from nature and the interactions between humans. Laozi, with his appreciation of nature, introduced the concepts of wu-wei, non-action and wu-zhi, not-knowing. His work has been spread all over the world, especially in Southeast Asia, serving as the canon of Daoism. This paper explores the notion of wu-wei and wu-zhi. A special epistemological view on knowledge acquiring will be introduced. Dewey's body learning and Laozi's wu-wei will be connected. The application of Daodejing and Laozi's philosophical idea in the modern age will be discussed.
\end{abstract}

Keywords: Dao and Wu, wu-wei, wu-zhi, knowledge boundary

\section{Laozi and Daodejing}

Laozi, who lived around $450 \mathrm{BC}$ in China, was an ancient Chinese philosopher and poet. $\mathrm{He}$ was an elder contemporary of Confucius (Lau, 1989). His worldview and philosophical view has influenced China and Southeast Asia widely. However, according to the Shi Ji (Records of the Historian), there were only two claimed facts in his entire biography. The first fact was the meeting between Laozi and Confucius, and the second fact was Laozi's journey to the west and the writing of Daodejing as a request from the Keeper of the Pass (Sima, 1979). He is traditionally regarded as the founder of Dao Jiao (philosophical Daoism), which has spread across Southeast Asia.

Daodejing and Zhuangzi altogether are the fundamental texts for philosophical Daoism. In this paper, however, Daodejing was the only textbook that has been studied and discussed. Daodejing's impact is far reaching. Even now, Daodejing, which is often referred to as the book of five thousand characters, has been listed as one of the most classic books in China. The main idea of wu-wei (non-action) and wu-zhi (not-knowing) retain their values in the twenty-first century. These two concepts have offered us a special pair of lens to view learning and knowledge.

Daodejing is no doubt the most frequently translated work in Chinese. There are more than thirty different translation versions of the book. The text of Daodejing is divided in two parts. Daojing, which includes the first 37 chapters of the book and Dejing, which is the rest of the book (chapter 38-chapter 81). Lau (1989) claimed that Laozi wrote Daodejing in two books at the request of the Keeper of the Pass.

In the rest of the paper, notions such as Dao, Wu, and Zhi will be introduced. Wu-wei, which means "non-action" in English, will be connected with Dewey's concept of body learning and the role of the body in the development of conscious learning. The notion wu-zhi, which is translated as "not-knowing," will raise a new and different epistemological view on teaching and learning. At last, the application of Laozi's Daodejing in the modern age will be explored.

\section{Dao and Wu}

Dao, which is simply translated to "the way" in English, is a pivotal concept in understanding Laozi's main idea of Daodejing. It is truly difficult to define a single character Dao without putting it in particular contexts. In mandarin, many words consist of the single character Dao and have been given various meanings from moral, path, to eloquent and so on. In Daodejing, Laozi claimed Dao is the source and the ground of all things. In the book, he tried to describe Dao as formless, nothingness, natural, pure, simplistic, approachable, and soft. In chapter 1, one characteristic of Dao is introduced. The first sentence reads as follows, "dao ke dao, fei chang dao, ming ke ming, fei chang ming" (Laozi, 2006), which means that if the Dao can be explained or described, is not the Dao that exists on earth, if the Name that can be named is not the eternal name. Therefore, the Dao that Laozi described, which is recognized as Daoism's cornerstone, is formless and impossible to be captured. Wu, which encompasses nothing or emptiness is the form of the Dao in Laozi's Daodejing. Thus Dao means everything in Laozi's mind.

In chapter 1, the second sentence reads as follows, "wu ming tiandi zhi shiye, you ming tiandi zhi muye" (Laozi, 2006), which can be translated as "the nameless (wu-ming, wu is the form of the Dao) is the origin of Heaven and Earth; the named is the mother of myriad things" (Lau, 1989). Laozi emphasized Dao and 
$\mathrm{Wu}$ in the first chapter. He was trying to tell the readers how important these two notions are. Later, he mentioned Dao several times. In chapter 42 of Daodejing, the idea of Dao as the creator of the universe are introduced as follows, "dao shengyi, yi sheng er, er sheng san, san sheng wanwu" (Laozi, 2006), which can be translated as, "Dao gives rise to one, one to two and two to three and three give rise to all things" (Lau, 1989).

\section{Wu-wei, Know-how and Wu-zhi}

The essence of Daodejing is the notion of wu-wei, which is translated literally in English as "nonaction". More significantly, in Daoism, wu-wei serves as an ethical or religious ideal. However, wu-wei in Daodejing, cannot be interpreted as simply as non-action. Laozi's wu-wei is a form of gesture or behavior that occurs without conscious thinking or consideration. Wu-wei is a form of action that one reacts to spontaneously. It is not a forcing action. For example, a professional basketball player dribbles while carrying out coach's tactics; this is wu-wei. A professional tennis player rallies the ball without using vision to aim; this is also wuwei. They each practice dribbling and swinging, until the motion becomes their new reflex. In chapter 63, it reads, "tianxia nanshi bizuo yu yi, tianxia dashi bizuo yu xi" (Laozi, 2006), which means complex things in the world must be achieved after simple accomplishments; big things are composed of smaller details (Lau, 1989). Referring back to the example of the professional basketball player, dribbling is the simple and detailed thing, while carrying out the coach's tactics is the complex and big thing. Buckingham (2014) advocated wu-wei is the way of behavior of the Daoist sage. He believed that Laozi unified the universe with his experience and therefore related effortlessly to the people and things of the world.

In addition, in this modern society, most leaders from various industries all began their careers from the front line of a company and conducted repetitive works at their earliest stages. The job they had accomplished was not only for the purpose of completion, but also a preparation for them to make complex and more critical decisions as a leader later in his or her career.

Dewey argued that know-how is a bodily habit, where experience is constituted by "thoughtless actions" (Dewey, 1922). The spontaneous action can be characterized as a kind of "bodily knowing," or "acted without thinking about it." Referring back to the example of the tennis player, swinging the paddle is an embodied habit. From Dewey's standpoint, a highly structured learning pattern is not hard to discover. Repetitive body motions form habits. The body absorbs motions and experiences as a learning process. Instinctual bodily reactions are habits working below direct consciousness. Similarly, wu-wei in Daodejing is a form of action as a bodily instinct. As Dewey argued the supreme of human body, Laozi also emphasized the significance of the relation between the body and nature. Laozi promoted that humans utilize all senses to comprehend nature.

Another important concept in Laozi's philosophy is wu-zhi, a word can be translated as no knowledge or not-knowing. The Chinese character zhi, a term that is often translated into English as, "knowledge", together with other characters, become words with a broader range of meanings, from "awareness" or "understanding" to "intelligence" (Buckingham, 2014). In contrast with wu-wei, which is a state of behavior habit, wu-zhi or notknowing is a state of self-understanding. Under most circumstances, people only know what they have been taught to know instead of knowing what they do not know (Kuhn, 2012). Knowledge is difficult to be transferred, and managed (Suzlanski, 1996; von Hippel \& Tyre, 1996).

In chapter 71 of Daodejing, the opening reads, "zhi bu zhi, shang yi; bu zhi zhi, bing yi” (Laozi, 2006), which means one knows that not-knowing is superior; not knowing but claiming one knows is a shortcoming. In an era of epistemology chaos, knowing not-knowing provides another epistemological view on the evaluation our educational research (Buckingham, 2014). All too often people focus on what to know and neglect how valuable it is to be aware of what people do not know. To know what learners do not know triggers creative ideas. Before taking any actions, a learner needs to assess his or her knowledge boundary. A learning model can be concluded from Laozi’s wu-zhi.

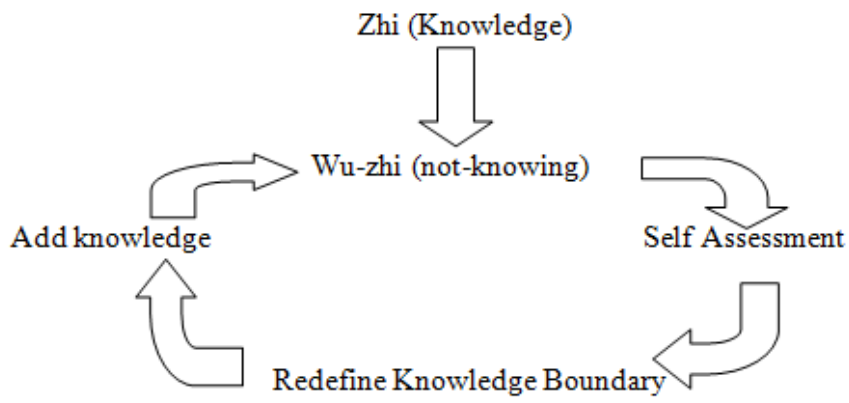

Figure 1. Zhi, Wu-zhi and Knowledge Boundary. 
After knowledge boundary has been assessed, the action of learning will be triggered. Learners will start to gain new knowledge to their knowledge reservoirs. Hence, redraw the knowledge boundary to explore more things that are outside of their knowledge boundary until new not-knowing is detected again. Buckingham (2014) proposed that Daodejing as a text with rich resources that offers us a new lens to teaching and learning. He articulated the communication of not-knowing as the central value in teaching and learning. Self-assessing the knowledge boundary has become one of the most important skills for self-directed learning (Langendyk, 2006).

\section{Daodejing in the twenty-first century}

Today, people are busy living but forget what they are living for. Many questions remain in this fast evolving society. Studying from those classic texts will shed light on our current journey of questing knowledge. From Daodejing, there are many truths people have neglected in the modern era, such as the proverb, "the more we eager to possess something permanent, the faster it slips away from our hands" (Kui, 2011). In chapter 9 of Daodejing, another example is provided, "chier yingzhi, buru qiji; chuaier ruizhi, buke changbao; jinyu mantang, mozhi nengshou" (Laozi, 2006), which can be translated as "rather than fill it to the brim by keeping it upright, better to have stopped in time; hammer it to a point, and the sharpness cannot be preserved forever, there may be gold and jade to fill a hall, but there is none who can keep them" (Lau, 1989). The proverb and the texts in Daodejing express a similar concept that people should stay humble and modest and do not be arrogant when one succeeds. As aforementioned, the idea of wu-wei has provided us a new way to learn by forming our bodily habit. The concept of wu-zhi has offered learners new lens to evaluate their knowledge by focusing on the things they do not know. Wu-wei and wu-zhi both encourage people to engage with the outside world and to face change.

From Daodejing, human beings are solely energy transporters from nature. Therefore, all artifacts, fames, wei, zhi, and other concepts human beings have created are part of nature, simply because nature is the root of all things on earth. The comprehensive observation of nature in Daodejing compensates for our individualistic subjective observation. That is one reason why Daodejing has been spread extensively. The book acts like a magnifier, assisting people to view things that exist but have been neglected for a really long time.

It is never too late to re-read the classic books to find invaluable lessons for our modern life. In this chaotic era, for the for-profit sector, globalization and political shifts have changed the way to behave and what to believe. The prevailing paradigm in education is constructivism-learners build their own truth. Learners are encouraged to assess their knowledge boundaries. Lewin (1951) accentuated the field theory, he argued that the field, which exists around people could be formed in any social structure. Technology has weakened the barriers for people to make changes and strengthened the driving forces to change. But the main theme of learning and development will become increasingly important serving as the center of organizations. Therefore, more selfassessments are required to examine one's knowledge boundary. The process from Zhi to Wu-zhi and back to Zhi is an endless circle.

\section{Conclusion}

Classical Chinese thoughts were predominantly practical in its orientation. The primary focus of early Chinese thinkers was a consideration of how to develop patterns of high moral standards that optimize interpersonal relations and the relationship between people and nature (Krueger, 2009). Ancient Chinese philosophers deeply experienced the feebleness of a single human being compared to the whole universe. There were countless obstacles that ancient Chinese failed to conquer, so they chose to remain in harmony with nature and learn from nature. Starting from sensing nature, appreciating nature to behaving with nature, ancient Chinese philosophers observed the world and tried to emulate nature to solve issues during human interactions. Laozi seldom explained anything to truth seekers. He simply chose to record how the world functions with plain, inornate, and genuine language.

Ironically, humans have limited vision to observe, flawed faculties to perceive the world, but are equipped with a brilliant brain to decrypt the reality. Therefore, continuously, conflicts occur. If the knowledge is the sea, and western researchers are standing on the shore or sailing a boat to examine the sea, whereas Chinese philosophers are swimming in the sea, drifting with the waves. As the whole world spinning, moving and changing, the only thing that a human being is capable of doing is trying to be in harmony with nature. If researchers are planning to study the world, they need to be a part of it, and the only way is to take wu-wei to face changes and to take wu-zhi to explore knowledge from a different epistemological standpoint.

\section{References}

[1]. Buckingham, W. Communicating not-knowing: education, Daoism and epistemological chaos [J]. China Media Research, 2014,10 (4), 10-18

[2]. Dewey, J. Human nature and conduct [M]. Mineola, NY: Courier Corporation, 1922.

[3]. Kui, W. K. Hegel's criticism of Laozi and its implications. [J]. Philosophy East and West, 2011,61(1), 56-79. 
[4]. Krueger, J. W. Knowing through the Body: The Daodejing and Dewey [J]. Journal of Chinese Philosophy, 2009,36(1), 31-52.

[5]. Kuhn, T. S. The structure of scientific revolutions [M]. Chicago, IL: University of Chicago press, 2012.

[6]. Laozi, Daodejing [M]. Guangzhou, GD: Guangzhou Press, 2006.

[7]. Lau, D. C. Tao te ching [M]. Hongkong: Chinese University Press, 1989.

[8]. Sima, Q. Selections from Records of the Historian Written [M]. Beijing: Foreign Languages Press, 1979.

[9]. Szulanski, G. Exploring internal stickiness: Impediments to the transfer of best practice with the firm [J]. Strategic Management. 1996, (17), 27-43.

[10]. von Hippel, E., M. Tyre. The mechanics of learning by doing: Problem discovery during process machine use [J]. Tech. and Culture, 1996, (37), 312-329.

[11]. Langendyk, V. Not knowing that they do not know: self-assessment accuracy of third-year medical students. Medical education [J].2006, 40(2), 173-179.

[12]. Lewin, K. Field theory in social science [M]. New York: Harper, 1951. 